\title{
Understanding Porous Water-Transport Plates in Polymer-Electrolyte Fuel Cells
}

\author{
Adam Z. Weber ${ }^{1, *}$ and Robert M. Darling ${ }^{2}$ \\ ${ }^{1}$ Lawrence Berkeley National Laboratory, \\ 1 cyclotron road, MS 70-108B, Berkeley, California 94720, USA \\ ${ }^{2}$ UTC Power, \\ 195 Governor's Highway, South Windsor, Connecticut 06074, USA
}

In this article, numerical simulations are used to compare polymer-electrolyte fuel cells with porous flow-field plates to cells with conventional solid plates. The model clarifies the role of the porous plates in humidifying dry reactant streams and managing liquid water. The influence of gas-diffusion-layer and bipolar-plate properties and coolant vacuum on the behavior of the cell is investigated.

Keywords: Polymer-electrolyte fuel cell; model; water-transport plate; water management; model

\footnotetext{
* Corresponding author: azweber@1bl.gov
} 


\section{Introduction}

It is widely known that for polymer-electrolyte fuel cells (PEFCs) water management is a critical aspect to their optimum and sometimes functional performance. This is especially true for cells operating below $100^{\circ} \mathrm{C}$ where liquid water is present. In such a system, there is a balance between flooding, i.e. water accumulation in the pores of the gas-diffusion layers (GDLs) or catalyst layers that inhibits reactants from reaching the reaction sites, and membrane dehydration that result in high ionic resistance. To optimize this balance, various schemes have been proposed and tested. These approaches include the use of microporous layers and more complex diffusion media [1], liquid water injection [2], system designs [3], wicking of liquid water [4] and the use of different flow pathways [5-9]. It is the goal of the latter two to enable self-humidification of the system, thereby reducing the cost and parasitic power losses of external components such as humidifiers.

A promising and extensively tested approach towards water management is the use of porous bipolar plates, known as water-transport plates (WTPs), as practiced by UTC Power [10-14]. Figure 1 shows a performance curve for a fuel cell with WTPs, and Figure 2 shows a schematic of the cell. Mass transport losses are minimal to $2.5 \mathrm{~A} \mathrm{~cm}^{-2}$. In fact, performance on dilute oxygen indicates that the limiting current density should approach $5 \mathrm{~A} \mathrm{~cm}^{-2}$ for saturated air at ambient exit pressure. While the performance and use of WTPs has been discussed previously, no detailed analysis or comparisons with conventional solid plates have been made in the literature. To gain understanding and make detailed comparisons, one must resort to simulation due to the challenging experimental effort of direct measurement and observation of water management inside an operating PEFC; water management is the most explored and debated PEFC modeling topic $[15,16]$. 
The WTPs perform two main functions. When there is excess water, the WTPs provide an escape path for liquid water such that it does not accumulate in the GDLs nor fill and block the gas channels. When the gas streams are not saturated, the WTPs provide water to evaporate into the gas channels in order to humidify them. To work properly, WTPs must meet certain key requirements. Firstly, they need to have similar electronic, thermal, and mechanical properties as solid bipolar plates. Secondly, they must have the correct pore-size distribution and hydrophilicity to form a wet seal and remain liquid filled such that hydrogen and oxygen cannot enter the coolant stream. Third, the water in the coolant stream must be run at a pressure below the reactant gases in order to provide a driving force for removal of liquid water from the cell. In addition, the plates must have sufficient permeability to allow for efficient water removal. The above issues are examined and discussed in more detail in this paper.

The structure of this paper is as follows. First, the model and property values are discussed. Next, simulations of WTP systems and solid-plate cells are compared and contrasted. Third, WTP properties and functioning are discussed in detail. Finally, conclusions are made.

\section{Model}

Our previously developed PEFC models are modified to analyze cells with WTPs [17-19]. The simulations are conducted using a pseudo 2-D approach, where a 1-D cell-sandwich model is run at various segments along the gas channels in a coflow arrangement. The 1-D sandwich is composed, as shown in Figure 2, of symmetric GDLs, anode and cathode catalyst layers, membrane, and either solid plates or WTPs. Unless otherwise noted, the parameters and properties of all of the layers, except the WTPs, are taken from the GDL1 fit in our previous paper [17]. Representative parameter values for WTPs are given in Table 1. For heat transfer, 
the values reported in our previous paper are used [18], with a heat-transfer coefficient of $1 \mathrm{~W}$ $\mathrm{cm}^{-2} \mathrm{~K}^{-1}$ for the solid-plate cell; the WTP cell is treated slightly differently as noted below. In both cells, it is assumed that the outsides of the gas-channel plates are in contact with coolant streams that remain fixed at the inlet temperature due to excess coolant flow. Other assumptions are steady-state operation, negligible gravity, local equilibrium (e.g., temperature is the same in all phases at a given location), and liquid-water product.

As noted, the simulations build on our previous models, and the reader is referred to references [17-19] and those contained therein for detailed discussions on the modeling approaches, equations, and parameter expressions as well appropriate historical references. In short, the membrane is treated using our hybrid approach that accounts for water and proton transport in both liquid- and vapor-equilibrated membranes; swelling is also considered. This approach uses concentrated-solution theory and a combined driving force for water movement. The catalyst layers are treated using a combined agglomerate-and-porous-electrode approach along with the membrane and GDL models. The GDLs are treated using our cut-and-rejoin bundle-of-capillaries approach with separate hydrophobic and hydrophilic domains. Liquid flow is modeled using Darcy's law, and gas flow is treated with Stefan-Maxwell and Knudsen diffusion along with Darcy's law (i.e., the gas phase is not isobaric). Furthermore, due to the intimate contact between phases, water vapor is assumed to be in equilibrium with any liquid water present inside the GDLs and catalyst layers. Nonisothermal phenomena are accounted for by an overall energy balance that contains heat conduction and convection along with heat sources and sinks including water phase change, reversible and irreversible heats of reaction, and Joule heating. 
To model WTPs instead of solid plates, one only needs to change the treatment of the gas channels. For a solid-plate cell, simultaneous mass and energy balances are used in the gas channels to obtain the necessary boundary conditions for gas-phase concentrations and temperature [18]. This treatment naturally allows for a prediction of where the cell becomes saturated and liquid water begins to exist for subsaturated inlet gases. For a WTP cell, the flux of liquid water through a WTP is modeled using Darcy's law; the associated enthalpy flux along with heat conduction forms the energy balance. The pressure and temperature of the coolant water serve as the necessary boundary conditions. At the interfaces between the WTPs and the gas-channels, simultaneous mass and energy balances are again used to determine gas-phase concentration and temperature, however, the gas channels do not contain any liquid water. Furthermore, the energy balance is modified in that there is no external heat transfer since this is accounted for explicitly using the energy flux from the WTPs, water enthalpy flux through the WTP pores and heat conduction through the solid regions. A comparison of the WTP and solidplate boundary conditions is given in the Appendix.

The rest of the boundary conditions are identical for the two systems, and are as follows. The interstitial concentrations and superficial fluxes between layers are continuous. The ionic current density is zero at the GDL / catalyst-layer interfaces, the electronic current density is zero at the membrane / catalyst-layer interfaces, the electric potential is arbitrarily set equal to zero at the anode gas channel, and the potential is set to the operating potential at the cathode gas channel. Unless noted below, operating conditions are $65^{\circ} \mathrm{C}$ reactant and coolant inlet temperatures, ambient reactant pressures, and 1.2 and 2.0 hydrogen and air stoichiometry, respectively. The coolant inlet pressure, when simulating a cell with WTPs, is 0.1 bar below the pressures of the feed gases. 


\section{Water-transport-plate and solid-plate operation comparison}

It is of interest to compare a cell with WTPs to one with traditional solid plates. To do this, polarization curves are simulated in which the properties of all of the materials between the plates are identical, with the only difference being the type of separator plate, and the corresponding boundary conditions. Figure 3 displays the resulting polarization curves with both saturated and low-relative-humidity $(25 \%)$ feed gases. Before proceeding to discuss the curves, it is worth mentioning that the GDL properties are taken from our modeling of a conventional solid-plate cell, and thus are not optimized for use with the WTPs, as is discussed in the next section. Similarly, a vacuum pressure of 0.1 bar is used for the simulations in this section, which is not necessarily optimal as examined in the next section. Even with the above issues, Figure 3 shows that the performance of the fuel cell with WTPs is better than that of the solid-plate cell under the conditions studied. In addition, although not shown, the WTP system outperforms the solid-plate design under the full range of humidity conditions.

For the saturated-feed case, the curves are essentially identical until high current densities where flooding in the cathode becomes problematic for the solid-plate design. However, the WTP system mitigates flooding and, therefore, does not exhibit the characteristic knee or bend in the polarization curve, indicative of mass-transfer limitations. For the higher potential region of the curve, the WTP does not have an appreciable impact on performance either detrimental or beneficial. If one looks at the low-relative-humidity curves however, there is a much larger benefit of having the WTPs. In fact, the WTP performance is similar to that for the saturated feed, because the gases are internally humidified. On the other hand, the solid-plate performance 
is much lower than for the corresponding saturated case. To examine the low-relative-humidity cases in more detail, the current-density profiles are given in Figure 4.

Figure 4 clearly demonstrates that the WTPs serve to humidify the inlet gas streams. This is seen in both the inset of Figure 4(b) as well as the fact that the current density decreases along the channel due to reactant consumption. The initial increase is due both to the temperature and humidity increase along the channel, and is the reason why the WTP low-relative-humidity performance is slightly lower than its saturated counterpart (see Figure 3). In practice, the difference between dry and saturated feeds is smaller than predicted because the catalyst layers do not extend to the edge of the WTPs as simulated here. In contrast, the solid-plate design has no way of humidifying the gases except through water production, and hence the gas streams do not reach saturation until near the outlet of the cell, as seen in the inset of Figure 4(a). This increase in humidification along the channel results in an increase in current density along the channel until the gases become nearly saturated and a liquid water exists (i.e., a dry to wet transition). The performance of the solid-plate cell could be improved by counter flowing the fuel and air. This is especially true for the low relative-humidity feeds, where a gain of around $30 \%$ in current density is achievable in a solid-plate cell due to the better humidification scheme that counterflow provides. However, this performance is still below that of the WTP cell, and furthermore, the WTP cell is insensitive to the relationship between the fuel and air flow directions. A final point is that since the gases remain saturated in a WTP cell, mechanical issues due to membrane swelling and shrinking are mitigated, thereby increasing fuel-cell life [20].

In addition to the ability of the WTPs to humidify unsaturated reactant streams internally, as shown in Figure 3, WTPs also demonstrate better performance for saturated streams. To analyze 
this behavior, the discrepancies at $0.4 \mathrm{~V}$ with saturated feeds are examined. Figure 5 gives the liquid-pressure and saturation profiles for both the solid-plate and WTP designs. From the curves, it is easy to see that the WTPs keep the membrane better hydrated and reduce cathode flooding. The WTPs increase the liquid pressure in the anode and decrease it in the cathode. Essentially, they do this by providing reservoirs of liquid water at a defined pressure. Since they are run under vacuum, they suck water from the cathode, while providing it to the drier anode. To understand this better, one can look at the water fluxes in the system.

Figure 6 shows the total and the liquid water fluxes for both designs. In the figure, the fluxes have been normalized by the proton flux in the membrane to yield the so-called $\beta$ value. Thus, the flux in the cathode GDL should be 0.5 more than that in the anode GDL after accounting for hydrogen and oxygen crossover; the value 0.5 is the dimensionless water production rate. The fluxes in the figure demonstrate that water is moving from the anode WTP through the cell to the cathode WTP in essentially the liquid phase. In fact, there is much more water moving in the WTP case than in the solid-plate case. This increase in water can help to flush contaminants (e.g., hydrogen peroxide) from the cell. The exact profiles are due to the interplay between the membrane, vapor, and liquid water fluxes. As described previously [18,21], the water-vapor flux moves away from the membrane and in opposition to the reactant gases due to a heat-pipe effect induced by the temperature gradient.

To examine the temperature issue in more detail, Figure 7 shows the temperature profiles at $0.6 \mathrm{~V}$ for both the WTP and solid-plate designs. A potential of $0.6 \mathrm{~V}$ is used instead of $0.4 \mathrm{~V}$ since the current densities of both cells are comparable (see Figure 3) and thus power and heat generation are also comparable. The cells exhibit similar temperature profiles since most of the heat-generation sources are the same. The main difference is the way in which heat is carried out 
of the PEFC sandwich, as well as the amount of liquid water moving through the cell. This is especially apparent in the increased rate of heat transfer inside the WTPs compared to traditional flow fields, which results in a smaller temperature increase as well as slightly smaller temperature gradients for the WTP system. Furthermore, the condensation from the heat-pipe effect is essentially carried out in the coolant plates and not the gas channel, thereby helping to keep the gas channels cooler. Overall, the use of WTPs results in a more nearly isothermal PEFC sandwich, which is probably better from a durability perspective since there is a lower likelihood of developing temperature heterogeneities. In addition, the smaller temperature rises mean that the cell can be operated at higher temperatures without as much concern about reactant dilution and possible gas-flow reversal. As mentioned, the temperature of the water in the coolant channels is taken to be a constant at $65^{\circ} \mathrm{C}$.

The above analysis and model do not account for the existence of liquid water in the gas channels. Liquid droplets in the reactant channels have been observed and cited in the literature as a cause of mass-transport limitations [22,23]. Not only do they affect performance, but they may lead to local fuel starvation and corrosion of carbon in the cathode catalyst layer [24]. For the WTP design, no liquid water is expected in the gas channels since it is removed through the porous plates. Figure 8 shows that pressure drop is the same linear function of current density for both the increasing and decreasing branches of the polarization curve shown in Figure 1. This experimental data suggests that the channels do not accumulate liquid water droplets.

\section{Aspects of water-transport plates}

In the preceding section, the benefits of WTPs in comparison to solid plates are elucidated. In this section, some aspects of working with WTPs are discussed in more detail. As 
mentioned above, there could be a concern of reactant gases entering the WTP and either crossing into the other reactant stream or leaving the cell, especially with subsaturated feeds. To examine this issue, one needs to look at the properties of the WTPs. From Table 1, it is clear that the WTPs contain small, hydrophilic pores to form a wet seal. One can calculate a bubble pressure using the Young-Laplace equation [25,26]

$$
p_{b}=\frac{2 \gamma \cos \theta}{r}>P_{\mathrm{G}}-P_{\mathrm{L}}
$$

where $P_{b}$ is the bubble pressure, $\gamma$ is the surface tension of water which is a function of temperature, $\theta$ is the contact angle of the WTP, and $r$ is the radius of a pore. The inequality stipulates that the bubble pressure should be greater than the difference between the gas and liquid pressures. Since the WTPs are hydrophilic, a pore radius of less than $1 \mu \mathrm{m}$ is enough such that reactant gases do not enter the WTP pores under typical operating conditions. Smaller pores could be used, but the liquid permeability decreases with pore size $[25,26]$ and may become problematic. Essentially, the bubble pressure sets a limit on the maximum pore size that is allowable for the WTP. Of course, this limit depends on the vacuum being applied to the liquid stream, since the inequality must hold.

One may wonder whether the WTP can deliver the water needed to humidity the stream, or if the WTP will dry out. The latter question is addressed in the next section, but as for the first, one can do an order-of-magnitude calculation to establish the evaporation rate. The maximum flux of water leaving the WTP and entering the dry inlet gas streams normalized by active area is approximately

$$
N=\left(\frac{a S h D}{L}\right) \frac{p_{\text {vap }}}{R T}
$$


where $a$ is the ratio of wetted channel area to active area, $S h$ is the Sherwood number, $D$ is the diffusion coefficient of water in air, $L$ is the hydraulic diameter, $p_{\text {vap }}$ is the vapor pressure of water evaluated at the temperature of the WTP wall, $R$ is the universal gas constant, and $T$ is the temperature. The Sherwood number for fully developed laminar flow through wetted square channels is 2.98 [27]. The hydraulic diameter, assuming that three of the four walls are wetted, is $1.33 s$, where $s$ is the length of a side. Assuming that adjacent channels are a distance $s$ apart, $a$ = 1.5. The maximum evaporation rate, according to this expression, is $1.4 \mathrm{~mol} \mathrm{~m}^{-2} \mathrm{~s}^{-1}$ at $65^{\circ} \mathrm{C}$ with $s=1 \mathrm{~mm}$. This is consistent with the hydration profile in Figure 4. For comparison, the water production rate at a current density of $1 \mathrm{~A} \mathrm{~cm}^{-2}$ is $0.05 \mathrm{~mol} \mathrm{~m}^{-2} \mathrm{~s}^{-1}$. Furthermore, the permeability of the WTPs is sufficient to enable this water to reach the gas-channel interface. For this quantity of water, another order-of-magnitude calculation is used

$$
N=\frac{\rho k P_{b}}{M \mu \delta}
$$

where $\rho$ is density of water, $k$ is permeability, $M$ is molecular weight, $\mu$ is viscosity, and $\delta$ is thickness. This yields a flux of approximately $11 \mathrm{~mol} \mathrm{~m}^{-2} \mathrm{~s}^{-1}$, when $\rho=1000 \mathrm{~kg} \mathrm{~m}^{-3}, k=10^{-15}$ $\mathrm{m}^{2}, P_{b}=99 \mathrm{kPa}, M=0.018 \mathrm{~kg} \mathrm{~mol}^{-1}, \mu=0.0005 \mathrm{~N} \mathrm{~m}^{-2} \mathrm{~s}^{-1}$, and $\delta=10^{-3} \mathrm{~m}$. This exceeds the maximum evaporation rate by 8 times. Thus, the flow of liquid water through the plates should be sufficient to humidify the reactant streams without causing the plates to empty, provided water is supplied continually supplied to the plates by the coolant stream.

The ability to have the coolant pressure below the reactant gases is a key part of the functioning of a WTP as mentioned above and deserves some discussion. If one defines the vacuum pressure as the pressure in the gas channel minus the liquid pressure in the channels of the WTP, then as it is increased there is a higher chance of reaching the bubble pressure. 
However, as it is increased, there is also a greater driving force to remove liquid water in the system. While the former aspect is relatively straightforward and involves the application of equation 1, the latter is a little more complex and is shown in Figure 9.

In Figure 9, as the liquid pressure is decreased, and assuming an ambient gas pressure of 1 bar (i.e., when the liquid pressure equals 1 bar, the capillary pressure is 0 bar), the saturation of the GDL also decreases; this is in agreement with Figure 5. However, as the saturation decreases, the liquid relative permeability, defined as the effective permeability divided by the maximum or saturated permeability, also decreases. This decrease creates a higher resistance for liquid water to exit the system. Thus, there is interplay where one wants enough vacuum to decrease the saturation but not too much such that the liquid-permeability is too low or that the bubble pressure is reached. In this fashion, Figure 9 along with equation 1 can be used to determine the correct operating vacuum pressure. Typically, a value around 0.1 to 0.2 bar is sufficient for the above criteria, although it depends on the GDL material as shown Figure 9. For the figure, two different GDLs are used, one that is completely hydrophilic, and another that is more hydrophobic and more typical of traditional GDL materials. The figure shows the interesting results that one does not necessarily want an entirely hydrophilic GDL in a WTP design since the necessary vacuum pressures to remove the GDL liquid may become prohibitive.

Due to the above interplay and the ability to control the vacuum pressure, it is worthwhile to examine its impact on performance. To do this, optimizations for peak power are done as a function of vacuum pressure; Figure 10 displays the optimization results. It is apparent that there are diminishing benefits as the vacuum pressure is increased, especially considering the chance of reaching the bubble pressure and the additional parasitic demands of the vacuum. The parasitic load associated with the vacuum pump is small relative to the parasitic load required to 
raise the gas pressures. A vacuum pressure of 0.15 bar is sufficient to gain the benefits of reduced saturations. Going to higher vacuum pressures does not improve the peak power since the cell is not as oxygen limited as the cell with solid plates. In addition, as one drives towards lower pressures, the membrane can begin to dry. This is evident in that the average anode GDL liquid saturation approaches zero at higher pressures, and also that $\beta$ becomes more negative. The reason for this is twofold. First, as shown in Figure 9, the lower saturations result in higher transport resistance for the liquid. Second, the higher vacuum pressure means that the pressure in the liquid-water reservoir is lower. Consequently, the liquid water does not have enough energy to overcome the increased flow resistance and reach the membrane. Once the liquid water cannot reach the membrane from the anode WTP, the value of $\beta$ decreases sharply and becomes negative, demonstrating that the membrane hydration is now coming from a back-flux of water produced at the cathode.

Finally, it is of interest to see how the performance with WTPs is affected by the GDL properties. To do this, polarization curves are simulated with varying GDL properties, as shown in Figure 11. The properties chosen to vary include the absolute permeability, the hydrophilic contact angle, and the fraction of hydrophilic pores. In addition, the absolute permeability of the WTPs was also varied over a couple of orders of magnitude with no discernable difference in performance (not shown). This indicates that smaller pores could be used in the WTP to increase the bubble pressure without a loss of performance, however this is unnecessary. Figure 11(a) shows the impact of increasing the GDL contact angle. As the contact angle approaches a value of $0^{\circ}$, the GDL material becomes more hydrophilic. Thus, a similar effect as that shown in Figure 9 will occur so that the relatively permeability and saturation of the GDLs increase. It is the increase in saturation that yields the perhaps counterintuitive trend seen in Figure 11(a), 
where a more hydrophobic medium performs better than a hydrophilic one. Of course, the vacuum pressure and fraction of hydrophilic pore also play a role in this analysis. As a point of reference, the base value used in the other simulations is $45^{\circ}$.

The fraction of hydrophilic pores has a similar effect as the contact angle on performance. As the fraction approaches 1, the GDL is entirely made up of hydrophilic pores of the given contact angle $\left(45^{\circ}\right.$ for this analysis). Figure $11(\mathrm{~b})$ shows that as the fraction of hydrophilic pores decreases, the performance increases, again caused by having a lower amount of flooding. However, there is an optimum because as the GDLs contain more hydrophobic pores, the increased resistance and lower relative permeability (see Figure 9) will cause localized flooding as well as inhibit water transport in the cell. While one might be concerned by the low relative permeability associated with this value (see Figure 9), Figure 11(b) demonstrates that it is not a major concern since varying the absolute permeability of the GDLs over a couple of orders of magnitude does not appreciably affect performance. In essence, the liquid flow resistance is not large enough to cause a build-up of liquid water in the system. The trends seen in this section generally hold for WTP cells, although the exact optimum pressures and points may shift depending on the specific cell and component properties.

\section{Conclusions}

In this paper, simulations were run to understand and compare the use of porous bipolar plates to solid plates. The porous plates serve as water-transport plates (WTPs) and provide both water for gas humidification and direct cooling, as well as remove water and decrease flooding. Thus, WTPs serve to mitigate mass transfer concerns in humidified systems and demonstrate substantially better performance than solid-plate designs with low relative-humidity feeds. The 
ability of the WTPs to enable uniform operation throughout the cell and keep the membrane hydrated should improve membrane durability. Some properties of the WTP system were also examined, including the effect of the vacuum pressure and the tradeoffs between providing water

and removing water in the system. Overall, the WTP system effectively meets and provides the critical water management necessary for optimum PEFC operation below $100^{\circ} \mathrm{C}$.

\section{Acknowledgements}

This work was supported by UTC Power and the Assistant Secretary for Energy Efficiency and Renewable Energy, Office of Hydrogen, Fuel Cell, and Infrastructure Technologies, of the U. S. Department of Energy under contract number DE-AC02-05CH11231. 


\section{Appendix: Gas-channel boundary conditions for solid-plate and WTP systems}

The model being used for the solid-plate and WTP cell comparisons is for the most part identical and the governing equations and parameters are given in references [17-19]. In this section, the differences between the two models are detailed. The use of WTPs instead of solid plates necessitates only a change in the boundary conditions used in the gas channels (GCs). For

both systems, simultaneous energy and mass balances are used in the GCs to determine the temperature and gas composition. For the cathode GC, the mass balances for oxygen and nitrogen are expressed as

$$
y_{\mathrm{O}_{2}}=1-y_{\mathrm{H}_{2} \mathrm{O}}-y_{\mathrm{N}_{2}} ; \quad \mathbf{N}_{\mathrm{O}_{2}}=\frac{0.21 \lambda_{\text {air }} I}{4 F}+\left.\mathbf{N}_{\mathrm{O}_{2}}\right|_{\mathrm{GDL}}
$$

and

$$
y_{\mathrm{N}_{2}}=0.79\left(1-y_{\mathrm{H}_{2} \mathrm{O}}\right) ; \quad \mathbf{N}_{\mathrm{N}_{2}}=\frac{0.79 \lambda_{\text {air }} I}{4 F}
$$

respectively, where $\lambda_{\text {air }}$ is the air stoichiometry, $I$ is the total current density, $\left.\mathbf{N}_{i}\right|_{\text {cGDL }}$ denotes the flux of species $i$ coming from the 1-D simulation (i.e., on the cathode GDL side of the cathode GDL / GC interface), $F$ is Faraday's constant, and $y_{i}$ is the gas-phase mole fraction of species $i$. The mass balance for the water vapor is more complex and different for the two systems.

For the solid-plate system, water can move from the GDL in the vapor phase or both the vapor and liquid phases. To account for this, it is assumed that if the pressure of the liquid in the GDL is less than the gas pressure in the GC, liquid water cannot exit the GDL and enter into the GC. Mathematically, the mass balance for vapor and liquid water can be expressed as 


$$
\begin{array}{cc}
y_{\mathrm{H}_{2} \mathrm{O}}=\frac{p_{\mathrm{H}_{2} \mathrm{O}}^{\text {vap }}}{p_{\mathrm{G}}} \quad \mathbf{N}_{\mathrm{H}_{2} \mathrm{O}, \mathrm{G}}=\left(\mathbf{N}_{\mathrm{O}_{2}}+\mathbf{N}_{\mathrm{N}_{2}}\right) \frac{y_{\mathrm{H}_{2} \mathrm{O}}}{1-y_{\mathrm{H}_{2} \mathrm{O}}} & \text { for } p_{\mathrm{L}} \geq p_{\mathrm{G}} \\
\mathbf{N}_{\mathrm{H}_{2} \mathrm{O}, \mathrm{G}}=\left.\mathbf{N}_{\mathrm{H}_{2} \mathrm{O}, \mathrm{G}}\right|_{\mathrm{GDL}}+\left.\mathbf{N}_{\mathrm{H}_{2} \mathrm{O}, \mathrm{L}}\right|_{\mathrm{GDL}}+y_{\mathrm{H}_{2} \mathrm{O}}^{\text {in }} \frac{\lambda_{\text {air }} I}{4 F}-\mathbf{N}_{\mathrm{H}_{2} \mathrm{O}}^{\text {cond }} ; & \text { for } p_{\mathrm{L}}<p_{\mathrm{G}} \\
y_{\mathrm{H}_{2} \mathrm{O}}=\frac{\mathbf{N}_{\mathrm{H}_{2} \mathrm{O}, \mathrm{G}}}{\mathbf{N}_{\mathrm{O}_{2}}+\mathbf{N}_{\mathrm{N}_{2}}+\mathbf{N}_{\mathrm{H}_{2} \mathrm{O}, \mathrm{G}}} &
\end{array}
$$

and

$$
\begin{array}{cll}
p_{\mathrm{L}}=p_{\mathrm{G}} ; & \mathbf{N}_{\mathrm{H}_{2} \mathrm{O}, \mathrm{L}}=\left.\mathbf{N}_{\mathrm{H}_{2} \mathrm{O}, \mathrm{L}}\right|_{\mathrm{GDL}}+\mathbf{N}_{\mathrm{H}_{2} \mathrm{O}}^{\text {cond }} & \text { for } p_{\mathrm{L}} \geq p_{\mathrm{G}} \\
\left.\mathbf{N}_{\mathrm{H}_{2} \mathrm{O}, \mathrm{L}}\right|_{\mathrm{GDL}}=0 ; \quad \mathbf{N}_{\mathrm{H}_{2} \mathrm{O}, \mathrm{L}}=\mathbf{N}_{\mathrm{H}_{2} \mathrm{O}}^{\text {cond }} & \text { for } p_{\mathrm{L}}<p_{\mathrm{G}}
\end{array}
$$

respectively, where $p_{k}$ is the (partial) pressure of phase (species) $k$, and $\mathbf{N}_{\mathrm{H}_{2} \mathrm{O}}^{\text {cond }}$ is the mass of water that condenses in the GC. For the WTP system, these equations are simplified since liquid water always exists and can move to/from the GDL. Thus, equations 6 and 7 become

$$
y_{\mathrm{H}_{2} \mathrm{O}}=\frac{p_{\mathrm{H}_{2} \mathrm{O}}^{\text {vap }}}{p_{\mathrm{G}}} ; \quad \mathbf{N}_{\mathrm{H}_{2} \mathrm{O}, \mathrm{G}}=\left(\mathbf{N}_{\mathrm{O}_{2}}+\mathbf{N}_{\mathrm{N}_{2}}\right) \frac{y_{\mathrm{H}_{2} \mathrm{O}}}{1-y_{\mathrm{H}_{2} \mathrm{O}}}
$$

and

$$
\left.\mathbf{N}_{\mathrm{H}_{2} \mathrm{O}, \mathrm{L}}\right|_{\mathrm{GC}}=0 ;\left.\quad \mathbf{N}_{\mathrm{H}_{2} \mathrm{O}, \mathrm{L}}\right|_{\mathrm{GDL}}=-\frac{k}{\overline{V_{\mathrm{w}}} \mu} \nabla p_{\mathrm{L}} ;\left.\quad \mathbf{N}_{\mathrm{H}_{2} \mathrm{O}, \mathrm{L}}\right|_{\mathrm{GDL}}=\left.\mathbf{N}_{\mathrm{H}_{2} \mathrm{O}, \mathrm{L}}\right|_{\mathrm{WTP}}+\mathbf{N}_{\mathrm{H}_{2} \mathrm{O}}^{\text {cond }}
$$

respectively, where $k$ is the permeability of the WTP, $\bar{V}_{w}$ and $\mu$ are the molar volume and viscosity of water, respectively, and the condensation occurs in the WTP. The second expression in equation 9 serves to calculate the liquid pressure in the GDL since the liquid pressure in the liquid stream at the edge of the WTP is known. Also, since the WTP contacts the GDL directly through the flow-field ribs, the liquid pressure does not have to equal the gas pressure and there is no liquid in the GCs themselves, as was the case for the solid-plate system. 
The final equation to be solved for the boundary conditions is the energy balance. For the solid-plate system, this has the form of

$$
\begin{aligned}
h\left(T-T_{\text {cool }}\right)= & -\left.k^{\text {eff }} \Delta T\right|_{\mathrm{GDL}}+\mathbf{N}_{\mathrm{H}_{2} \mathrm{O}}^{\text {cond }} \Delta H_{\text {vap }}+H_{\mathrm{G}}^{\text {in }}\left(\frac{\lambda_{\text {air }} I}{4 F} \frac{1}{1-y_{\mathrm{H}_{2} \mathrm{O}}^{\text {in }}}\right)-H_{\mathrm{G}}\left(\mathbf{N}_{\mathrm{O}_{2}}+\mathbf{N}_{\mathrm{N}_{2}}+\mathbf{N}_{\mathrm{H}_{2} \mathrm{O}, \mathrm{G}}\right) \\
& +\left.H_{\mathrm{G}}\right|_{\mathrm{GDL}}\left(\left.\mathbf{N}_{\mathrm{H}_{2} \mathrm{O}, \mathrm{G}}\right|_{\mathrm{GDL}}+\left.\mathbf{N}_{\mathrm{O}_{2}}\right|_{\mathrm{GDL}}\right)-H_{\mathrm{L}}\left(\mathbf{N}_{\mathrm{H}_{2} \mathrm{O}, \mathrm{L}}-\left.\mathbf{N}_{\mathrm{H}_{2} \mathrm{O}, \mathrm{L}}\right|_{\mathrm{GDL}}\right)
\end{aligned}
$$

where $H_{k}$ is the molar enthalpy of phase $k$, which can be calculated from its composition and handbook values $[28,29]$, the superscript "in" means the inlet to the channel in the gas-flow direction, $h$ is the heat-transfer coefficient per superficial area to the coolant stream, and $T_{\text {cool }}$ is the coolant-stream temperature. For the WTP system, there is liquid flow through the WTP, and the energy balance becomes

$$
\begin{aligned}
\left.\frac{C_{\mathrm{p}}}{L}\left(T-T_{\text {cool }}\right) \mathbf{N}_{\mathrm{H}_{2} \mathrm{O}, \mathrm{L}}\right|_{\mathrm{WTP}}= & -\left.k^{\text {eff }} \Delta T\right|_{\mathrm{GDL}}+H_{\mathrm{G}}^{\text {in }}\left(\frac{\lambda_{\text {air }} I}{4 F} \frac{1}{1-y_{\mathrm{H}_{2} \mathrm{O}}^{\text {in }}}\right)-H_{\mathrm{G}}\left(\mathbf{N}_{\mathrm{O}_{2}}+\mathbf{N}_{\mathrm{N}_{2}}+\mathbf{N}_{\mathrm{H}_{2} \mathrm{O}, \mathrm{G}}\right) \\
& +\left.H_{\mathrm{G}}\right|_{\mathrm{GDL}}\left(\left.\mathbf{N}_{\mathrm{H}_{2} \mathrm{O}, \mathrm{G}}\right|_{\mathrm{GDL}}+\left.\mathbf{N}_{\mathrm{O}_{2}}\right|_{\mathrm{GDL}}\right)
\end{aligned}
$$

where $C_{\mathrm{p}}$ is the heat-capacity of the liquid and the left-side expression stems from solving the energy balance in the WTP with a boundary condition of $T=T_{\text {cool }}$ at the coolant-stream boundary $(L)$ of the WTP.

The set of boundary conditions for the aGC/aGDL interface is essentially the same as the above equations, except that the directions of the fluxes from the anode GDL will have the opposite sign as those from the cathode GDL, and since pure hydrogen is used, there is no equation for the inert (i.e., no $\mathrm{N}_{2}$-type equations). 


\section{References}

[1] Z. G. Qi, A. Kaufman, J. Power Sources, 109 (2002) 38-46.

[2] D. L. Wood, Y. S. Yi, T. V. Nguyen, Electrochim. Acta, 43 (1998) 3795-3809.

[3] D. P. Wilkinson, H. H. Voss, K. Prater, J. Power Sources, 49 (1994) 117-127.

[4] T. Yang, P. Shi, J. Electrochem. Soc., 153 (2006) A1518-A1524.

[5] M. Watanabe, H. Uchida, M. Emori, J. Electrochem. Soc., 145 (1998) 1137-1141.

[6] F. N. Büchi, S. Srinivasan, J. Electrochem. Soc., 144 (1997) 2767-2772.

[7] M. S. Wilson, Fuel Cell with Interdigitated Porous Flow-Field, 1995, The Regents of the University of California Office of Technology Transfer: U.S.

[8] J. S. Yi, T. V. Nguyen, J. Electrochem. Soc., 146 (1999) 38-45.

[9] L. Wang, H. Liu, J. Power Sources, 134 (2004) 185-196.

[10] C. Reiser, Ion Exchange Membrane Fuel Cell Power Plant with Water Managament Pressure Differentials, 1997, UTC Fuel Cells: United States. 5,700,595.

[11] D. J. Wheeler, J. S. Yi, R. Fredley, D. Yang, T. Patterson, L. VanDine, J. New Mater. Electrochem. Syst., 4 (2001) 233-238.

[12] R. Baldwin, M. Pham, A. Leonida, J. McElroy, T. Nalette, J. Power Sources, 29 (1990) 399-412.

[13] R. Zaffou, J. S. Yi, H. R. Kunz, J. M. Fenton, Electrochemical and Solid State Letters, 9 (2006) A418.

[14] J. S. Yi, D. Yang, C. King, AIChE J., 50 (2004) 2594-2603.

[15] A. Z. Weber, J. Newman, Chemical Reviews, 104 (2004) 4679-4726.

[16] C. Y. Wang, Chemical Reviews, 104 (2004) 4727-4766.

[17] A. Z. Weber, J. Newman, J. Electrochem. Soc., 152 (2005) A677-A688.

[18] A. Z. Weber, J. Newman, J. Electrochem. Soc., 153 (2006) A2205-A2214.

[19] A. Z. Weber, R. M. Darling, J. Newman, J. Electrochem. Soc., 151 (2004) A1715-A1727.

[20] A. B. La Conti, M. Hamdan, R. C. McDonald, in Handbook of Fuel Cells: Fundamentals, Technology, and Applications, Vol. 1, W. Vielstich, A. Lamm, and H. A. Gasteiger, Editors, 3, pp. 647-662, John Wiley \& Sons, Inc., New York (2003). 
[21] Y. Wang, C. Y. Wang, J. Electrochem. Soc., 153 (2006) A1193-A1200.

[22] F. Y. Zhang, X. G. Yang, C. Y. Wang, J. Electrochem. Soc., 153 (2006) A225-A232.

[23] M. A. Hickner, N. P. Siegel, K. S. Chen, D. N. McBrayer, D. S. Hussey, D. L. Jacobson, M. Arif, J. Electrochem. Soc., 153 (2006) A902-A908.

[24] T. W. Patterson, R. M. Darling, Electrochemical and Solid State Letters, 9 (2006) A183A185.

[25] F. A. L. Dullien, Porous Media: Fluid Transport and Pore Structure, 2nd ed., Academic Press, Inc., New York 1992.

[26] J. Bear, Dynamics of Fluids in Porous Media, Dover Publications, Inc., New York 1988.

[27] F. P. Incropera, D. P. Dewitt, Fundamentals of Heat and Mass Transfer, 3rd ed., John Wiley \& Sons, New York 1990.

[28] CRC Handbook of Chemistry and Physics, 64th ed., R. C. Weast, Editor, CRC Press, Boca Raton, FL 1983.

[29] R. H. Perry, D. W. Green, Perry's Chemical Engineers' Handbook, 7th ed., J. O. Maloney, Editor, McGraw-Hill, New York 1997. 


\section{Captions}

Figure 1. Experimental performance of a cell with WTPs. Operating conditions: ambient reactant exit pressures, $14 \mathrm{kPa}$ coolant vacuum, $65^{\circ} \mathrm{C}$ air exit temperature, fuel and air stoichiometries of 1.25 and 1.67 , respectively. The active area of the cell is $400 \mathrm{~cm}^{2}$.

Figure 2. Schematic of the 1-D modeling domain and function of the WTPs.

Figure 3. Polarization curves for both 25 and $100 \%$ relative-humidity feeds for both a WTP and a solid-plate system. The parameters and conditions are as stated in the text.

Figure 4. Along-the-channel values for the current density for the (a) solid-plate and (b) WTP systems at $0.6 \mathrm{~V}$ with $25 \%$ relative-humidity feeds. The insets in the graphs are the relative humidities in the anode and cathode gas channels.

Figure 5. Liquid-pressure (a) and saturation (b) profiles for both the WTP and solid-plate systems at $0.4 \mathrm{~V}$ with saturated feeds. The WTPs or gas channels are not shown in detail in the figure in order to magnify the other effects.

Figure 6. Total and liquid dimensionless water fluxes for both the WTP (black) and solid-plate (grey) cells at $0.4 \mathrm{~V}$ and with saturated feeds.

Figure 7. Through-plane temperature distributions for both the WTP and solid-plate systems at $0.6 \mathrm{~V}$ with saturated feeds. The dashed lines indicate the assumed linear temperature profile in the solid plates, which is not explicitly calculated due to the use of an external heat-transfer coefficient (see Appendix and reference [18]). The dotted lines represent the layer boundaries as shown in Figure 6.

Figure 8. Experimental pressure-drop data as a function of current density for the cathode gas channels demonstrating laminar flow and no occlusion by water droplets in a WTP cell. 
Figure 9. GDL saturation and relative permeability as a function of liquid pressure (gas pressure is 1 bar) for two different hydrophilic pore fractions.

Figure 10. Optimum peak power for a given vacuum pressure at $65^{\circ} \mathrm{C}$ with saturated feeds. Also shown are the average cathode and anode GDL saturations and the value of the net water flux per proton flux, $\beta$, for the given optimum power.

Figure 11. Polarization curves for different GDL properties values including the (a) contact angle and (b) the fraction of hydrophilic pores and absolute permeability for saturated feeds and a vacuum pressure of 0.1 bar.

Table 1. Water-transport-plate properties. 
Table 1. Water-transport-plate properties.

\begin{tabular}{lrl}
\hline \multicolumn{1}{c}{ Parameter } & Value \\
\hline PSD properties & & \\
$\quad$ Characteristic radius & 0.5 & $\mu \mathrm{m}$ \\
Characteristic spread & 0.2 & \\
Bulk porosity & 0.3 & \\
Thickness & 0.15 & $\mathrm{~cm}$ \\
Electronic conductivity & $20 \mathrm{~S} \mathrm{~cm}{ }^{-1}$ \\
Thermal conductivity & $30 \quad \mathrm{~W} \mathrm{~cm}^{-1} \mathrm{~K}^{-1}$ \\
Absolute permeability & $1 \times 10^{-11} \mathrm{~cm}^{2}$ \\
Fraction of hydrophilic pores & 1 & \\
Contact angle & $45 \quad \circ$ \\
\hline
\end{tabular}




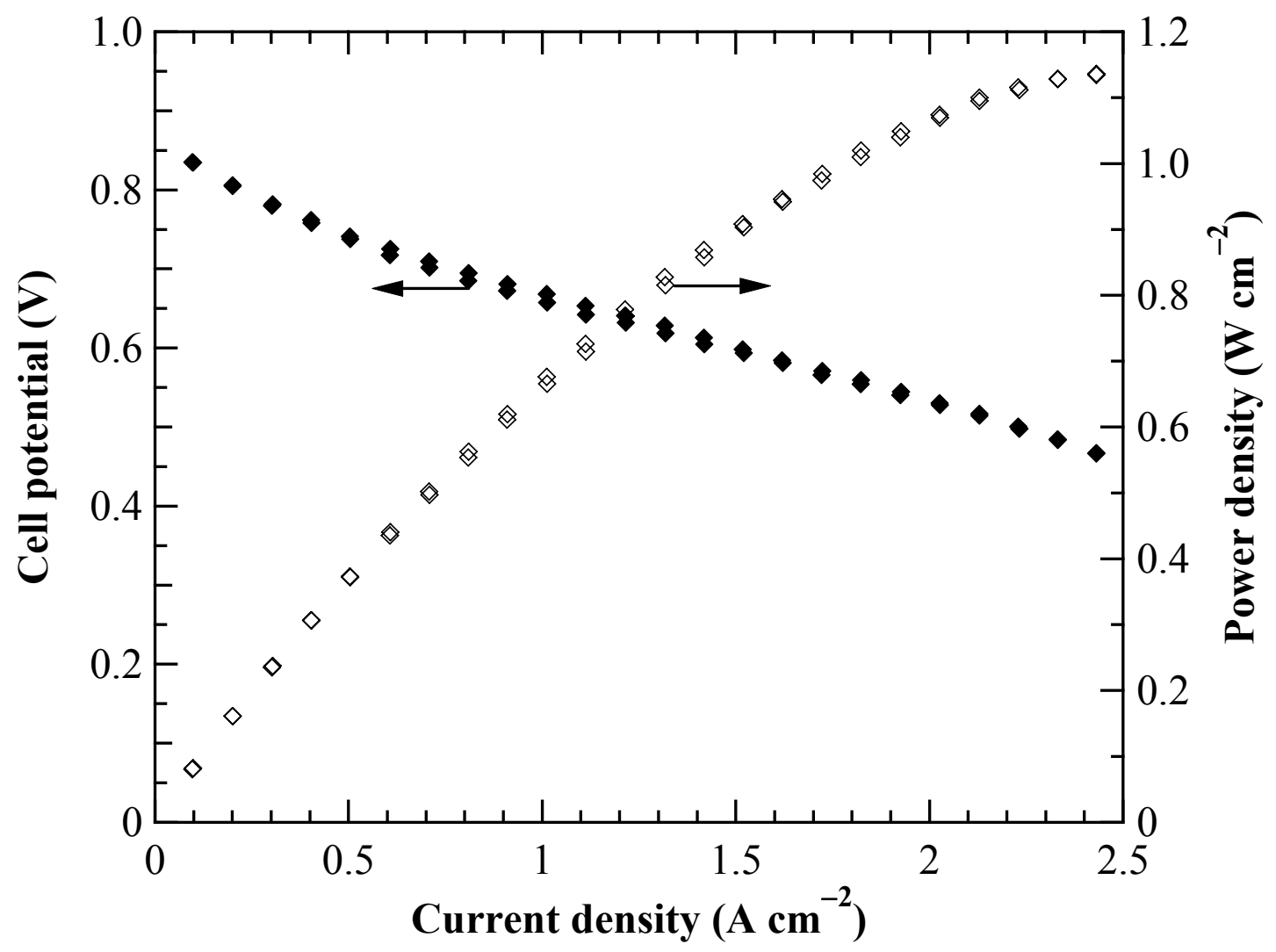

Figure 1. Experimental performance of a cell with WTPs. Operating conditions: ambient reactant exit pressures, $14 \mathrm{kPa}$ coolant vacuum, $65 \mathrm{oC}$ air exit temperature, fuel and air stoichiometries of 1.25 and 1.67, respectively. The active area of the cell is $400 \mathbf{c m}^{2}$. 


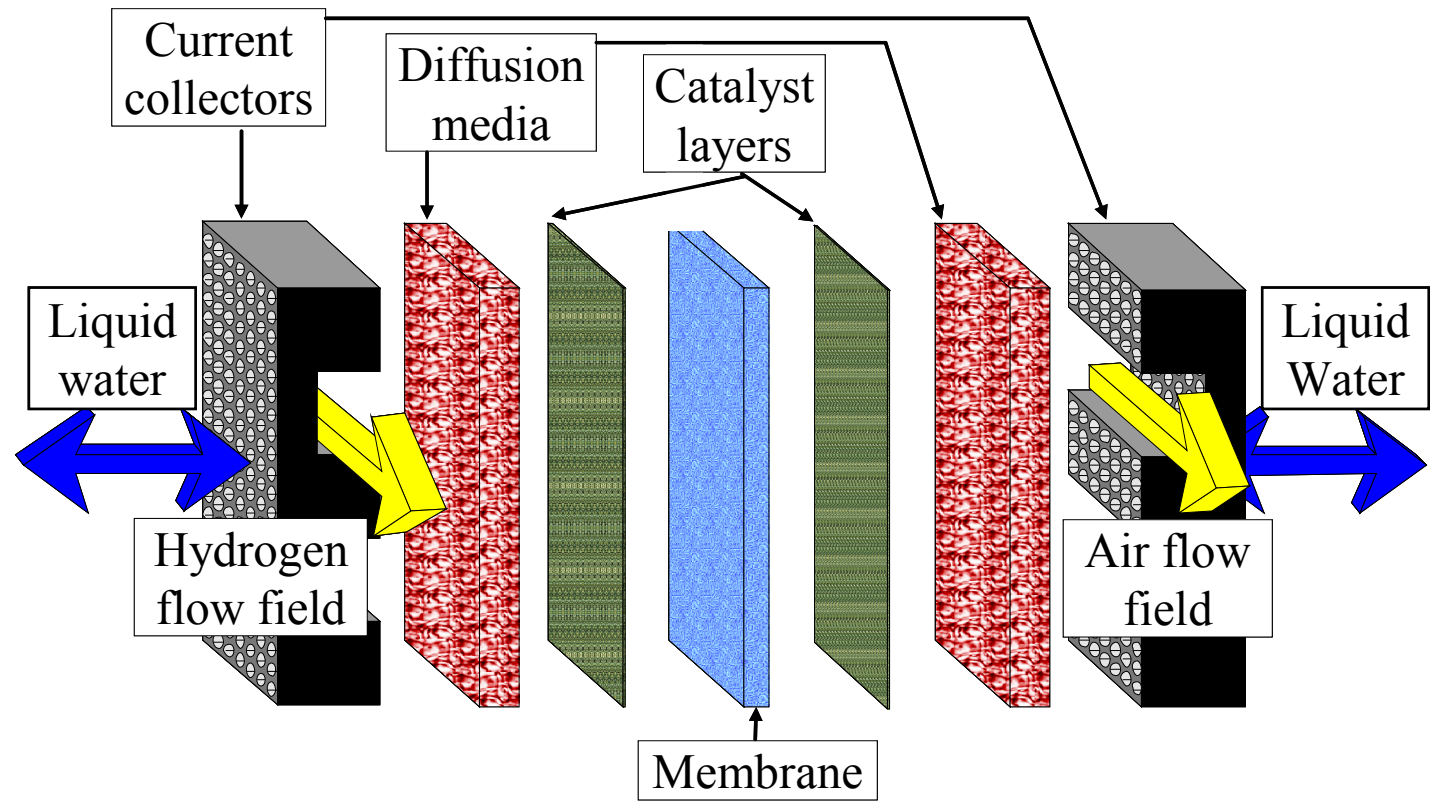

Figure 2. Schematic of the 1-D modeling domain and function of the WTPs. 


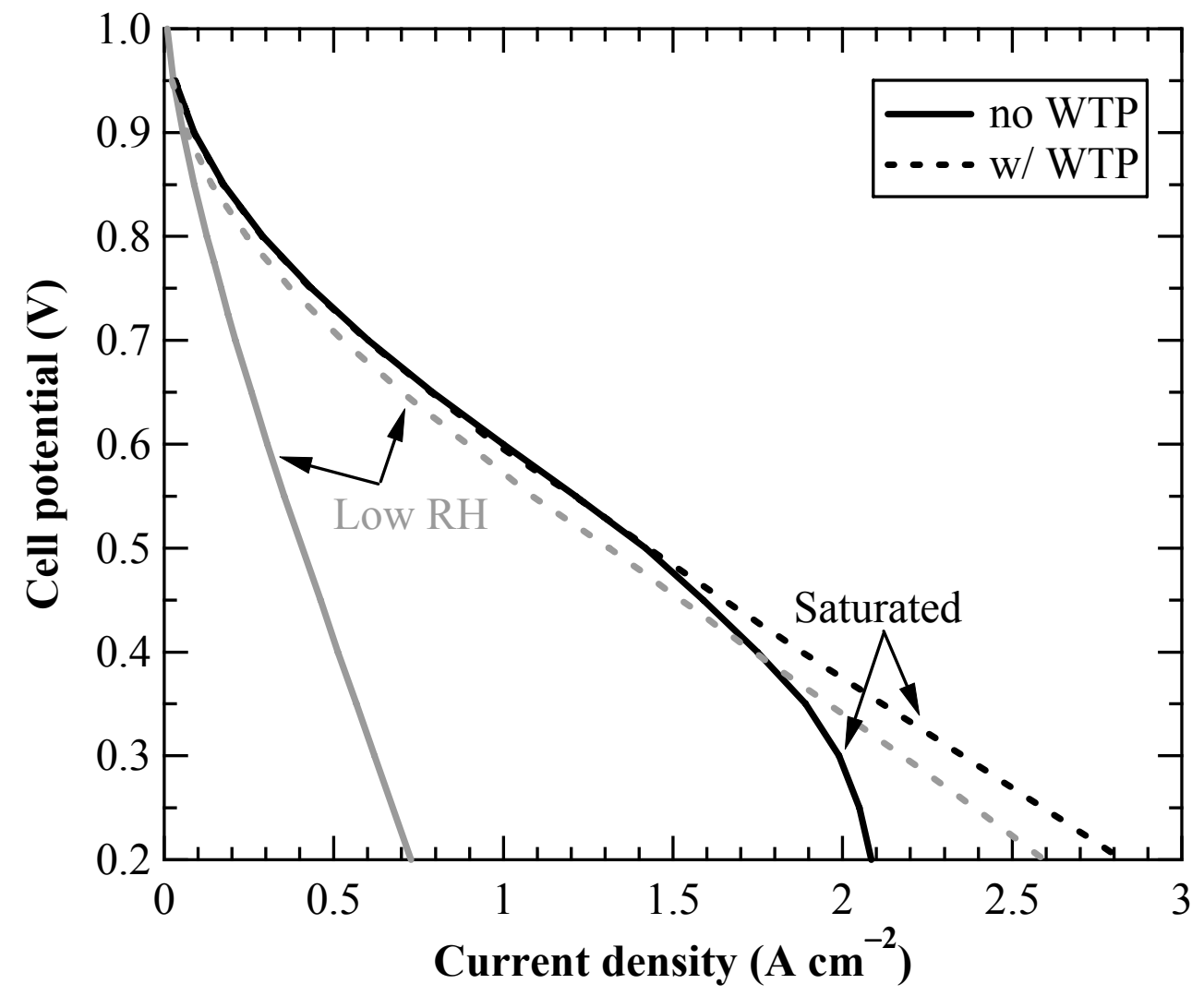

Figure 3. Polarization curves for both 25 and $100 \%$ relative-humidity feeds for both a WTP and a solid-plate system. The parameters and conditions are as stated in the text. 


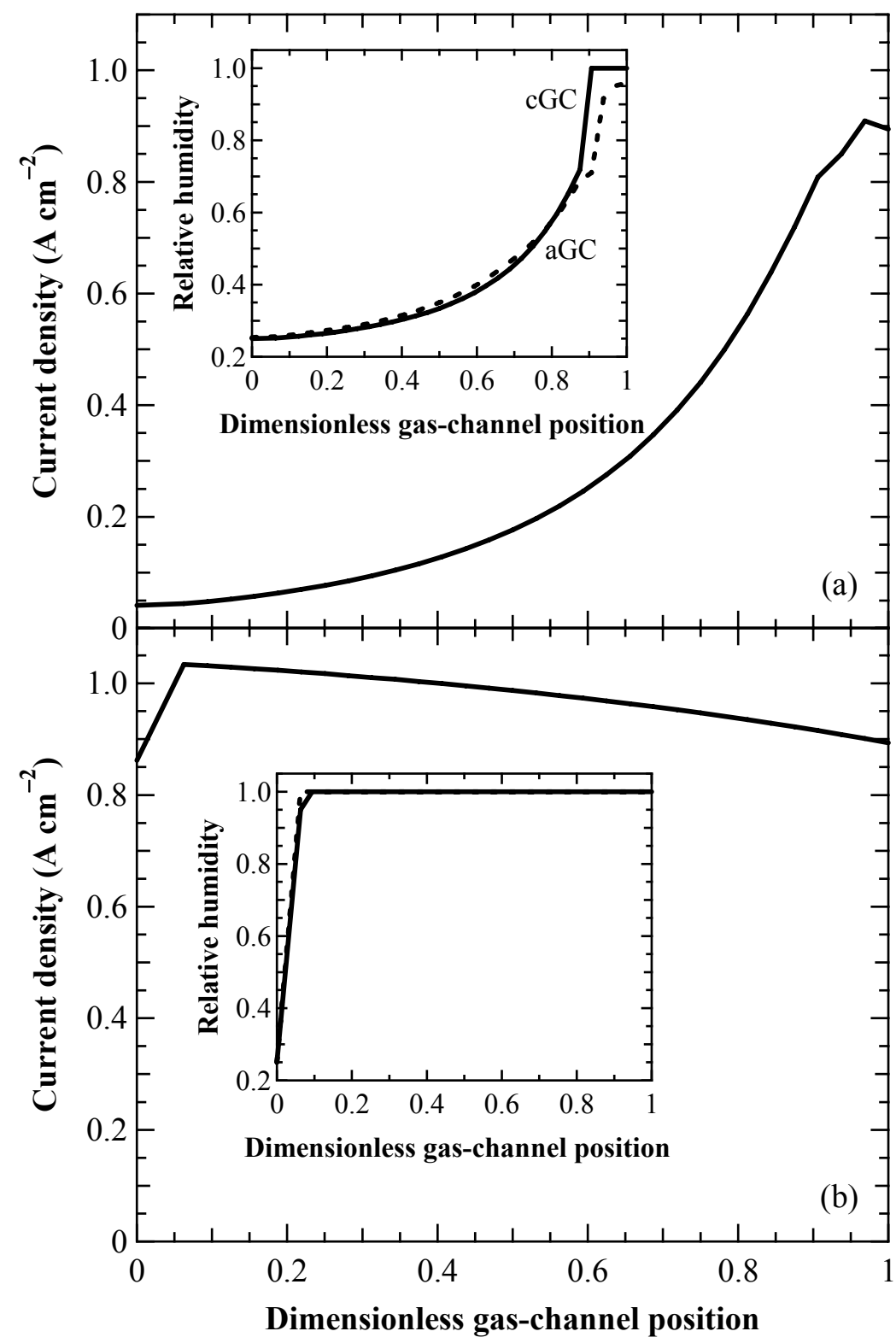

Figure 4. Along-the-channel values for the current density for the (a) solid-plate and (b) WTP systems at $0.6 \mathrm{~V}$ with $25 \%$ relative-humidity feeds. The insets in the graphs are the relative humidities in the anode and cathode gas channels. 


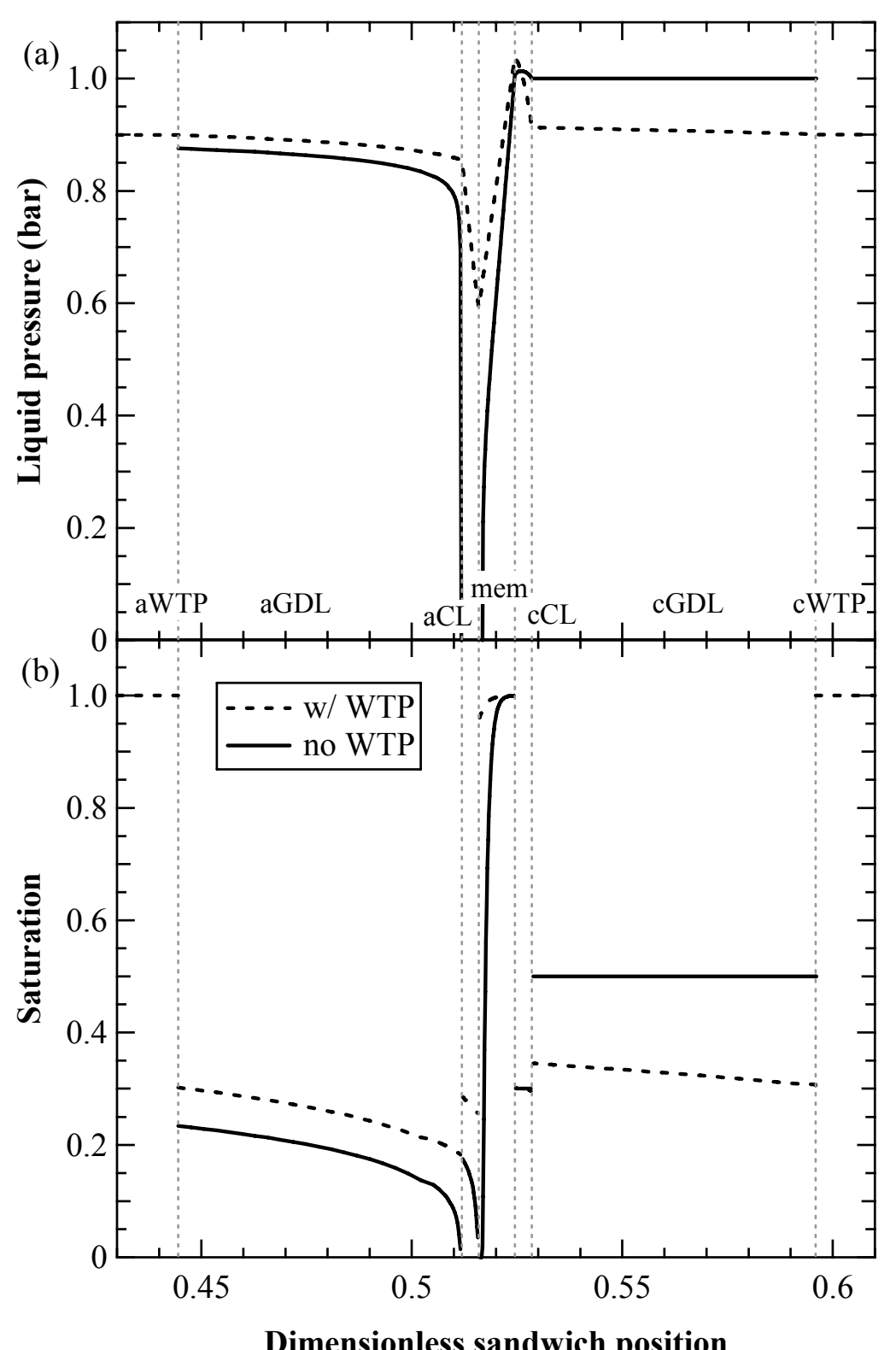

Dimensionless sandwich position

Figure 5. Liquid-pressure (a) and saturation (b) profiles for both the WTP and solid-plate systems at $0.4 \mathrm{~V}$ with saturated feeds. The WTPs or gas channels are not shown in detail in the figure in order to magnify the other effects. 


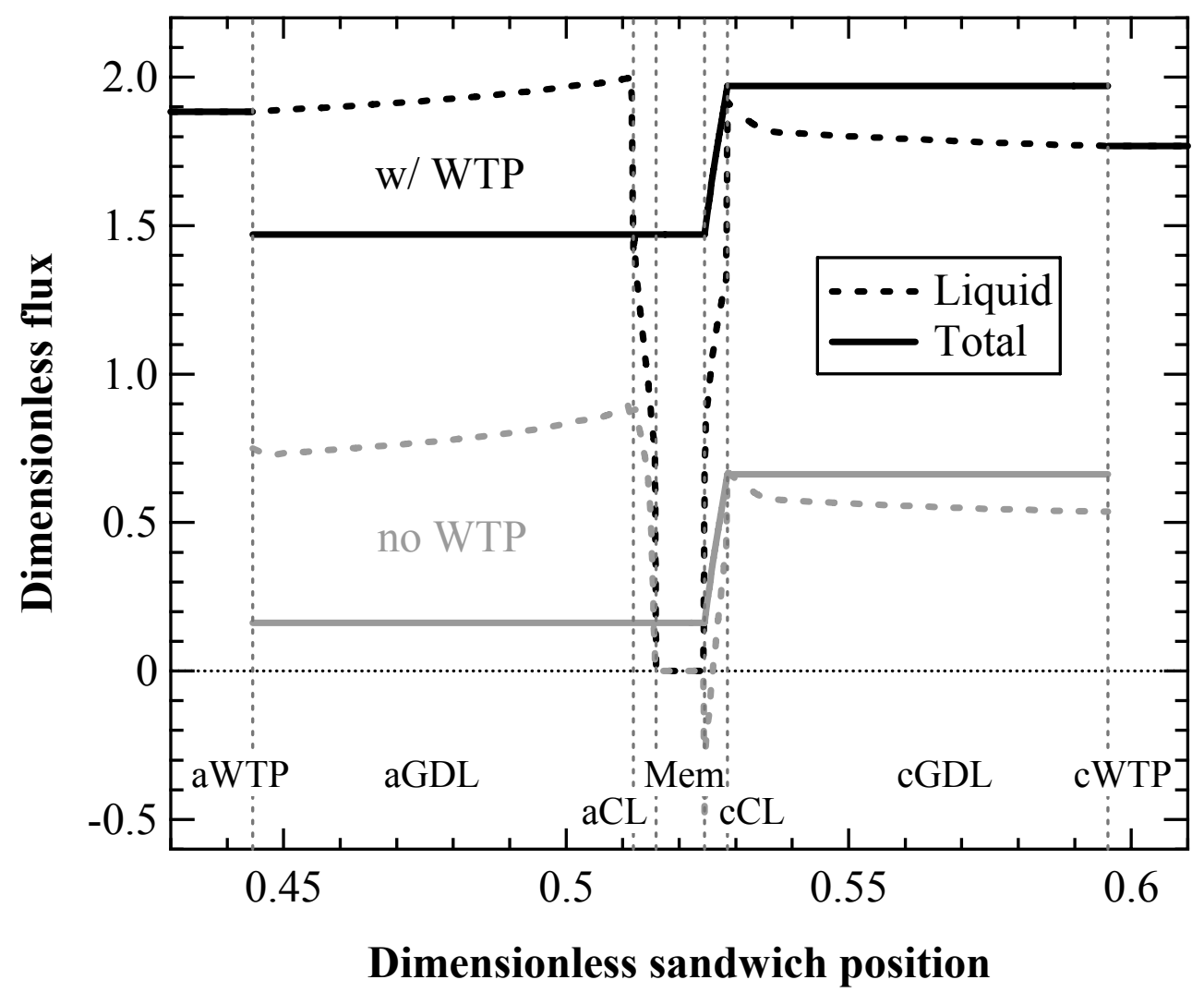

Figure 6. Total and liquid dimensionless water fluxes for both the WTP (black) and solidplate (grey) cells at $0.4 \mathrm{~V}$ and with saturated feeds. 


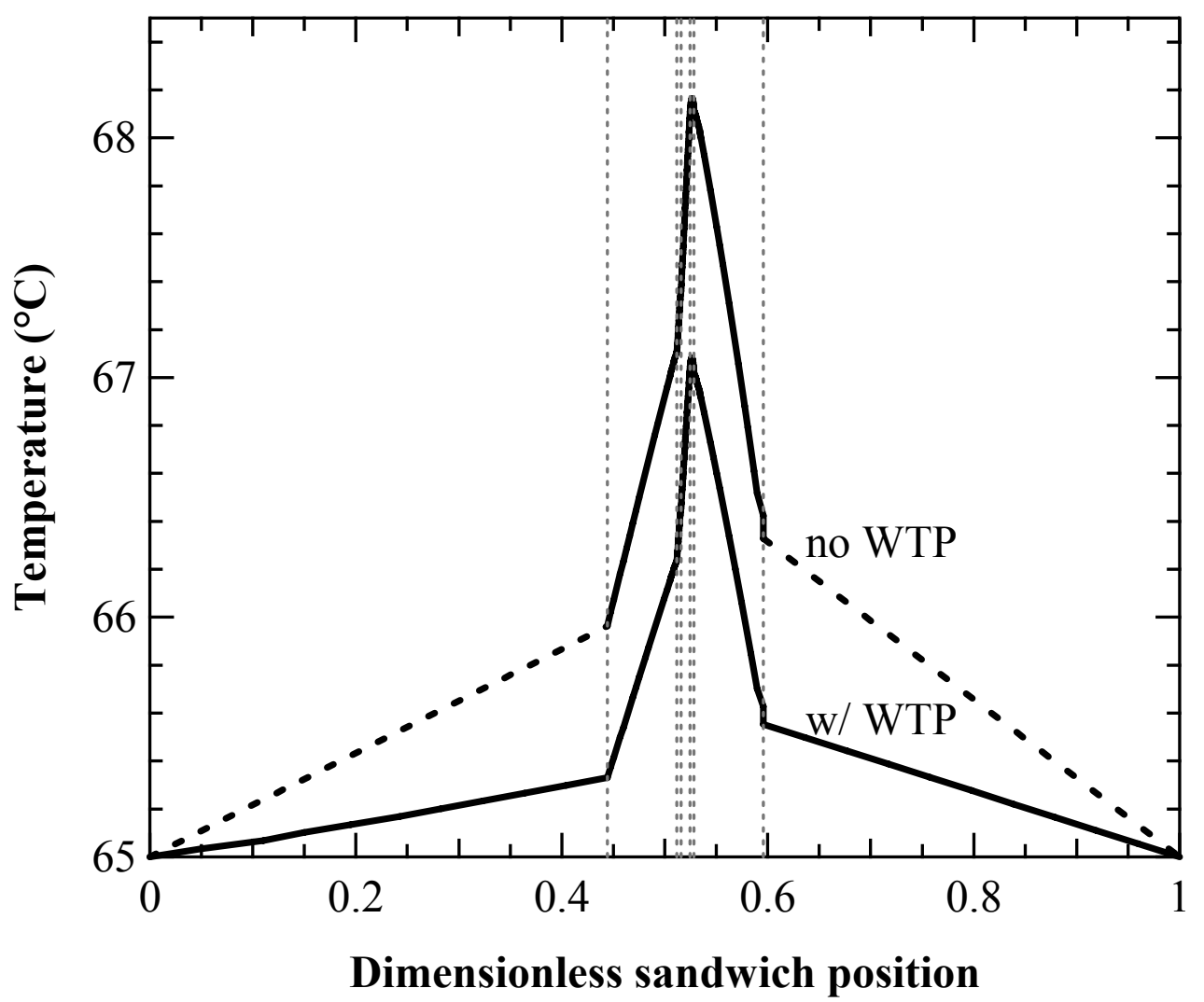

Figure 7. Through-plane temperature distributions for both the WTP and solid-plate systems at $0.6 \mathrm{~V}$ with saturated feeds. The dashed lines indicate the assumed linear temperature profile in the solid plates, which is not explicitly calculated due to the use of an external heattransfer coefficient (see Appendix and reference [18]). The dotted lines represent the layer boundaries as shown in Figure 6. 


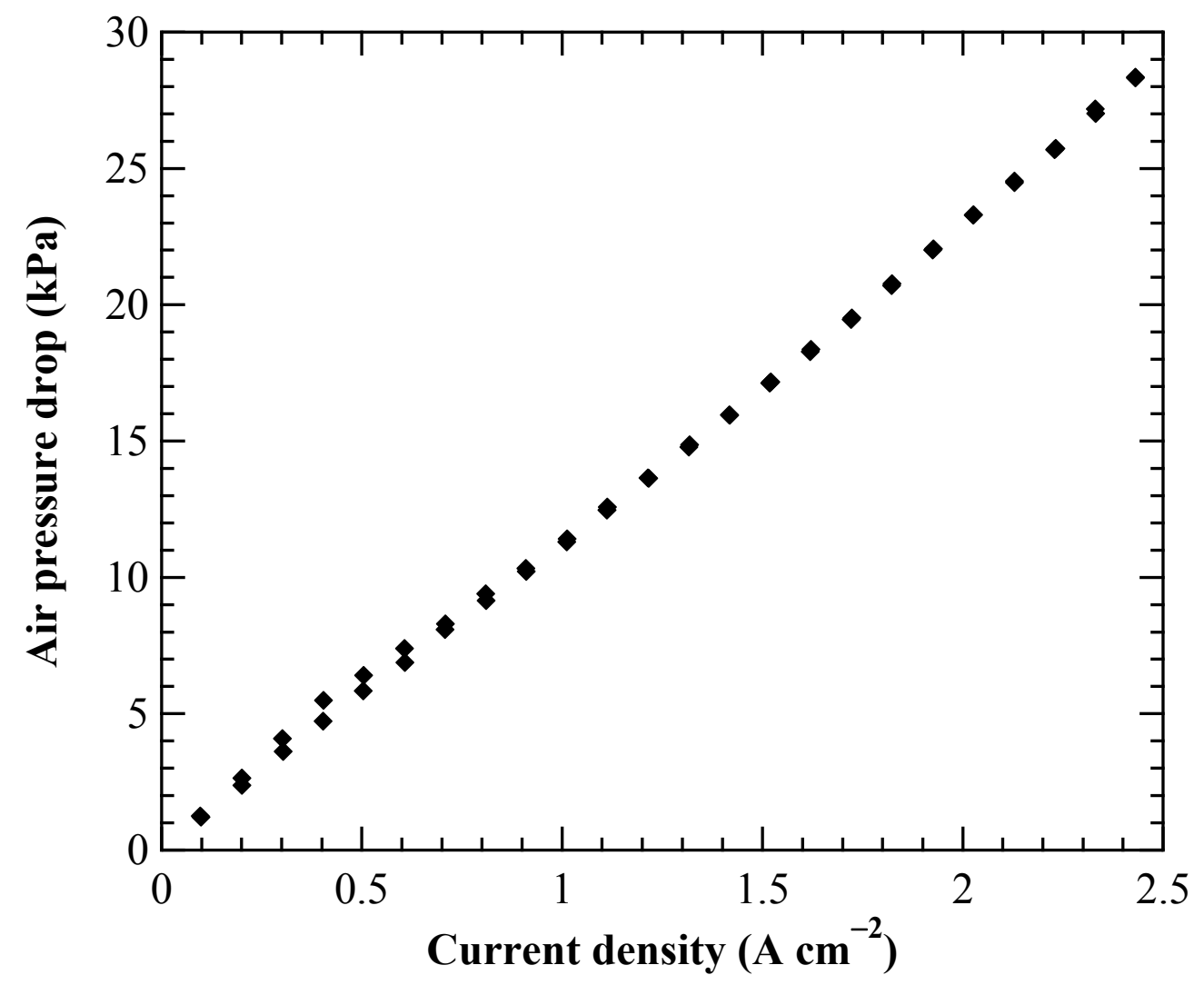

Figure 8. Experimental pressure-drop data as a function of current density for the cathode gas channels demonstrating laminar flow and no occlusion by water droplets in a WTP cell. 


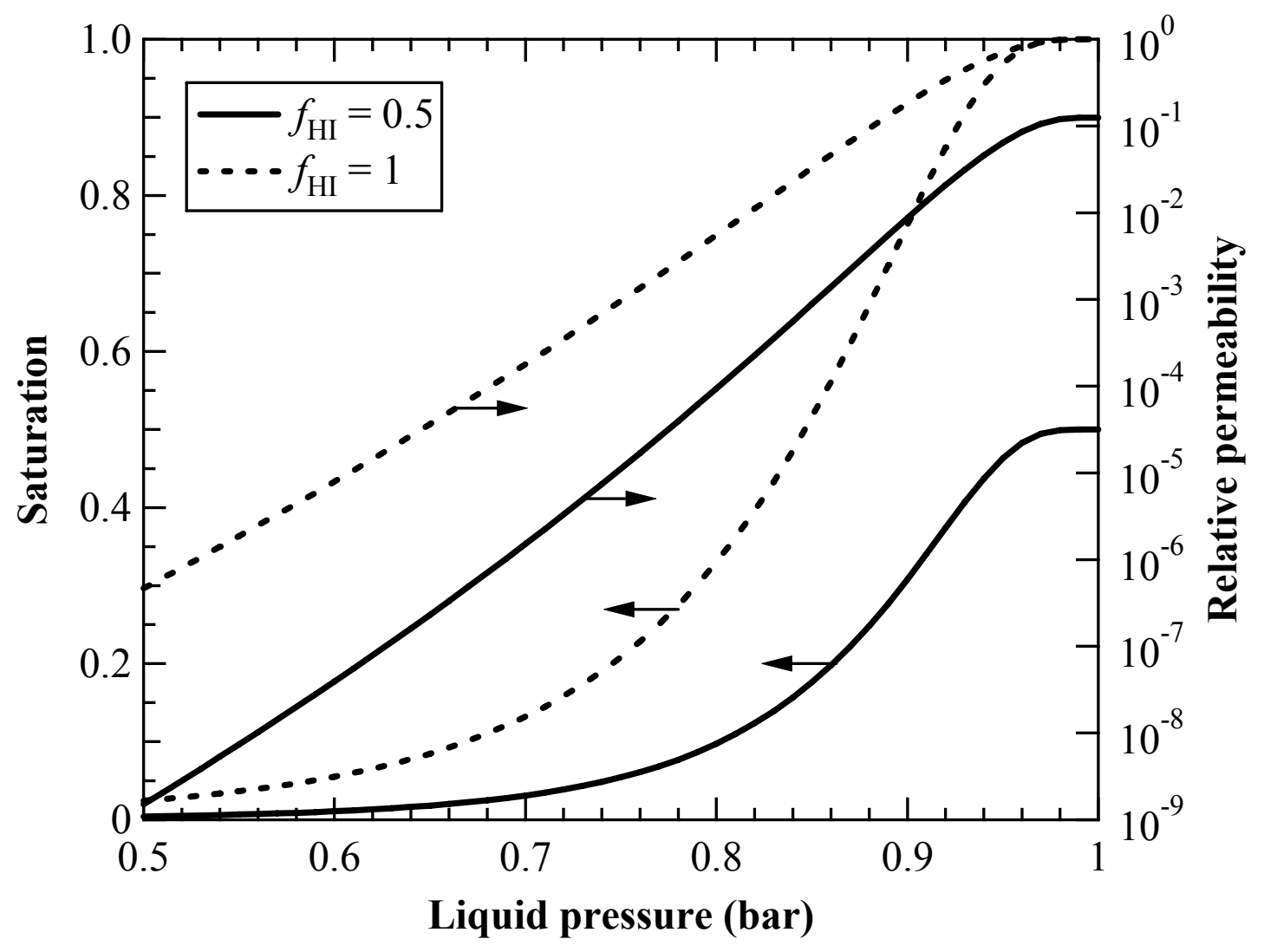

Figure 9. GDL saturation and relative permeability as a function of liquid pressure (gas pressure is 1 bar) for two different hydrophilic pore fractions. 


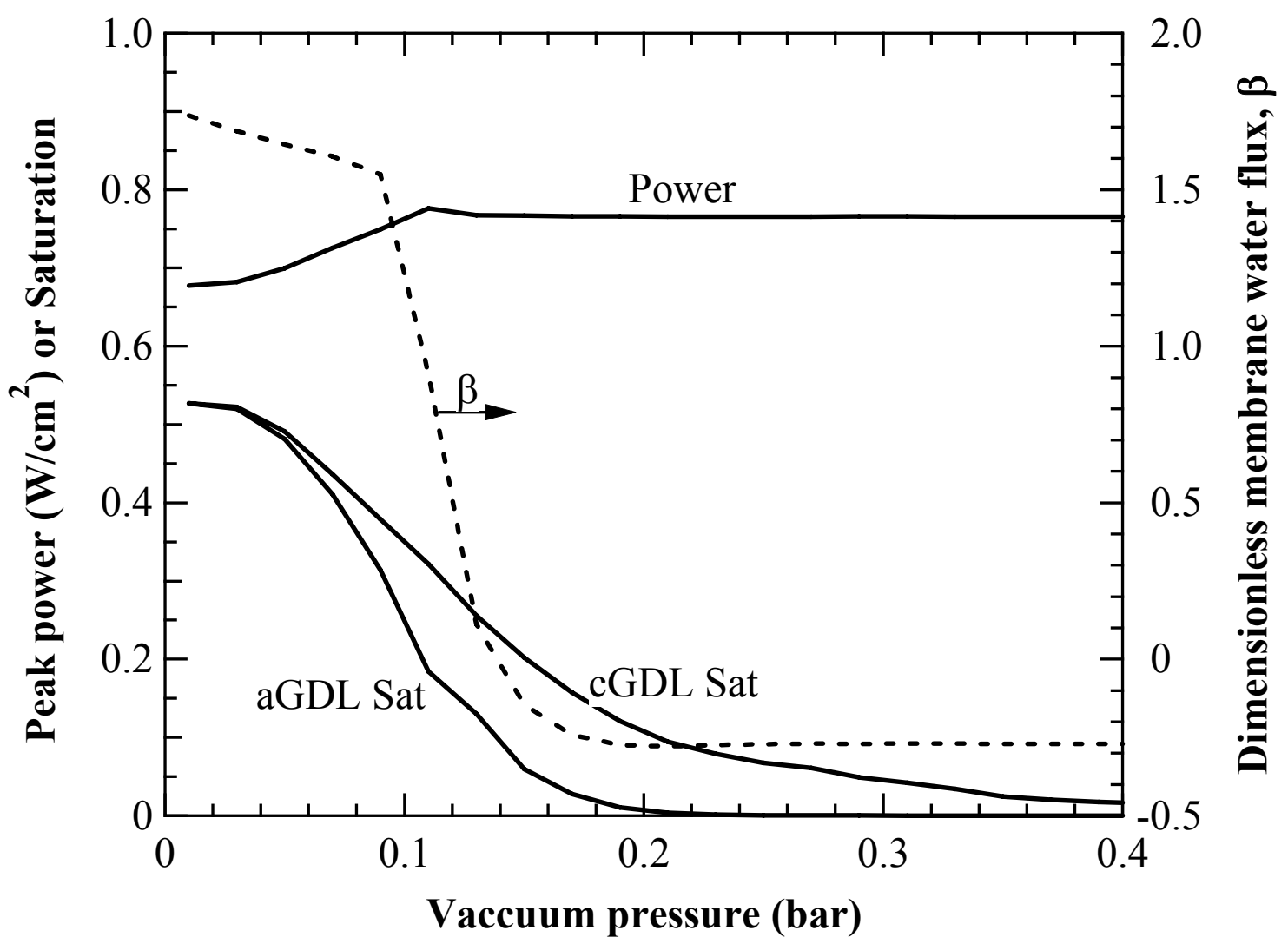

Figure 10. Optimum peak power for a given vacuum pressure at $65^{\circ} \mathrm{C}$ with saturated feeds. Also shown are the average cathode and anode GDL saturations and the value of the net water flux per proton flux, , for the given optimum power. 


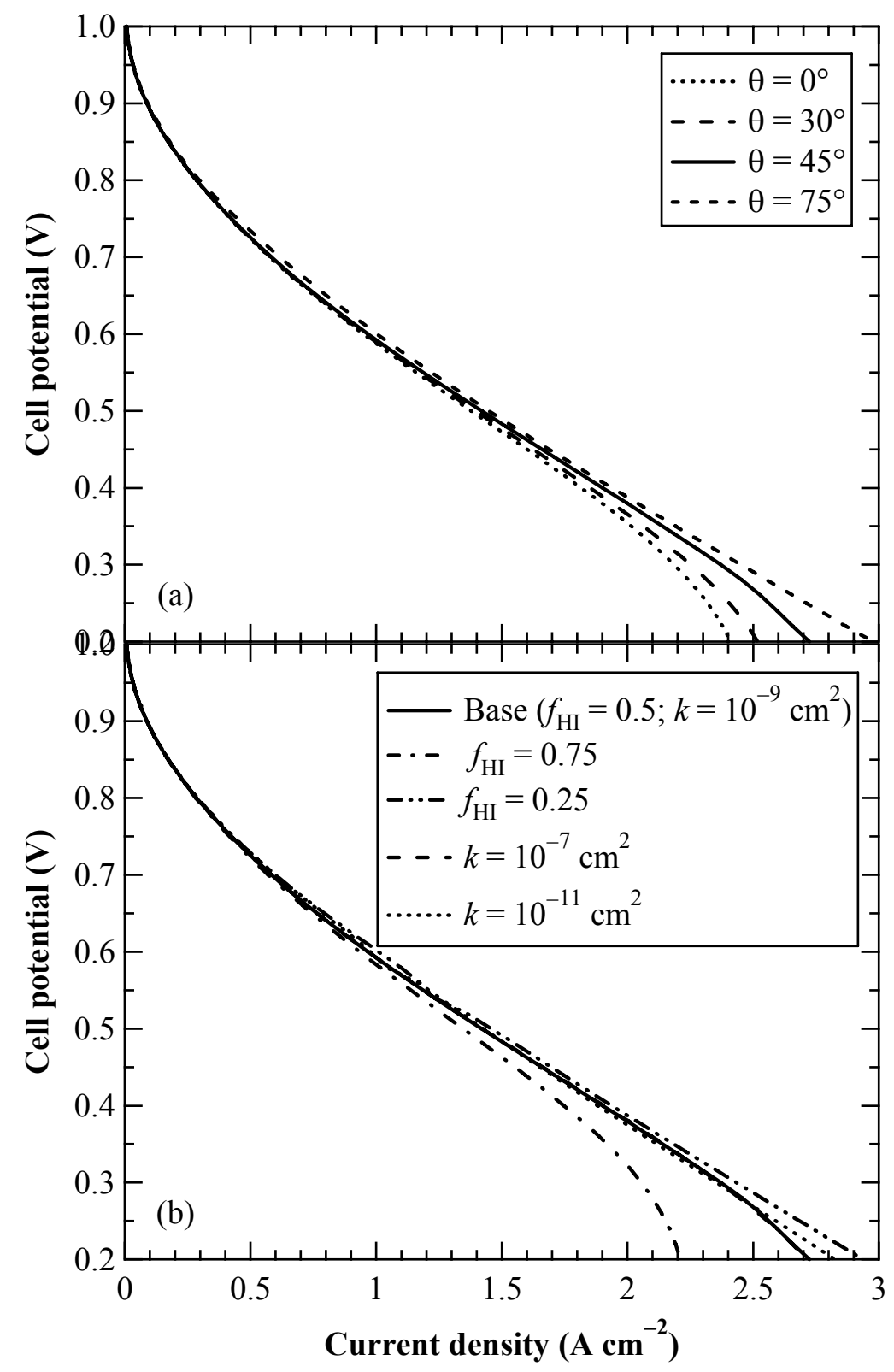

Figure 11. Polarization curves for different GDL properties values including the (a) contact angle and (b) the fraction of hydrophilic pores and absolute permeability for saturated feeds and a vacuum pressure of 0.1 bar. 